\title{
Submucosal Uterine Fibroid in Grand Multipara Woman: A Case Report
}

\author{
Muhammad Rusda ${ }^{1 *}$, Arvitamuriany Triyanthi Lubis ${ }^{1}$, Muhammad Ramadhan Hisworo ${ }^{1}$, Andrina Yunita Murni Rambe ${ }^{2}$ \\ ${ }^{1}$ Department of Obstetrics and Gynecology, Endocrinology Reproductive Division, School of Medicine, Universitas Sumatera \\ Utara, Medan, Indonesia; ${ }^{2}$ Department of Otorhinolaryngology, School of Medicine, Universitas Sumatera Utara, Medan, \\ Indonesia
}

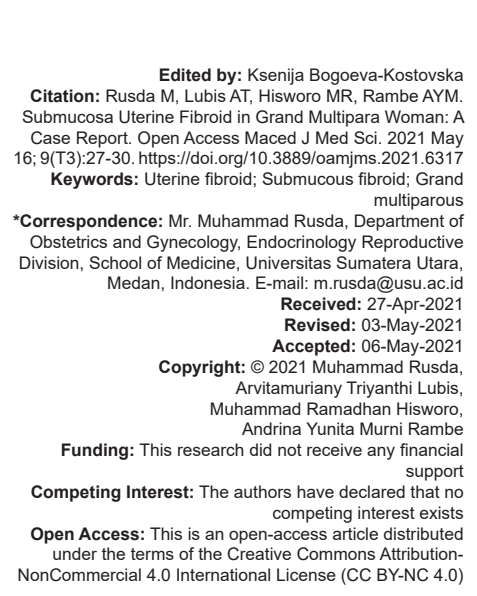

\begin{abstract}
AIM: The objective of the study was to report and analyze a case that diagnosed with submucous uterine fibroid in grand multiparity woman.

CASE REPORT: A 49-year-old woman, P7A0, came with chief complaints vaginal bleeding that has been experienced for 1 year ago getting worse in 2 months. Her general condition was within normal limit and there was no abnormality in physical examination, by vaginal examination, there was blood in the vagina, origin from the external uterine orifice, bimanual examination showed anteflexion uterus with normal size, right and left adnexa within normal limits. From transvaginal ultrasound, we found submucous uterine fibroid size $3 \mathrm{~cm} \times 3 \mathrm{~cm}$, we decided to perform total abdominal hysterectomy.

CONCLUSION: Hysterectomy is a progressive and definitive uterine fibroid procedure for women who do not wan
\end{abstract} to conceive and/or women over $40-50$ years of age, in particular.

\section{Introduction}

One of the most common benign tumors is the uterine fibroid of the women reproductive system. The incidence rate is about $50-60 \%$ and mostly occurs in women of reproductive age [1]. Uterine fibroid is a myometrial tumor with a prevalence of up to $70-80 \%$, which tends to vary with a variety of variables, including age, race, and likely geographical location. Submucosal uterine fibroid diagnosis is normally made with one or a combination of transvaginal ultrasonography (TVUS) hysteroscopy and radiological techniques, saline infusion sonography, and magnetic resonance imaging that important to determine a number of factors including uterine fibroids that distinguish adenomyosis and confirmed the exact location of submucosal uterine fibroid, as well as the number, size, and extent of myometrial penetration of each submucosal uterine fibroid. It is important to determine how close the relationship between submucous myomas to uterine serous. When leiomyoma is near to or attached to the serosal layer due to an increased risk of perforation and serious injury, transcervical resection is not considered [2].
Several numbers of conditions and symptoms may be caused or related to uterine fibroid response to medical therapy. Some procedures have been developed to treat one or both abnormal uterine bleeding (AUB) and to minimize uterine fibroid volume. However, there is no basis or evidence for the use of medical treatment to treat infertility or recurrent miscarriage in women with uterine fibroid submucosa. There is evidence that a variety of medical strategies for the treatment of heavy menstrual bleeding (HMB) may be useful at least for some patients with submucosal uterine fibroid, although there were varies evidence, because of the difference of study design characteristic. For example, in one prospective study, the levonorgestrel intrauterine system (LNG-IUS) has been shown to significantly reduce HMB in women with type 2 uterine fibroids [2].

Higher failure rates and subsequent reoperation rates in patients treated with uterine artery embolization (UAE) have been reported in submucosal uterine fibroids and AUB patients than patients without any bleeding symptoms. A study by Radeleff et al. (2009) suggests that around $50 \%$ of dominant submucosal fibroids were completely expelled during the follow-up [3]. 
There have also been cases of persistent vaginal discharge in women with submucosal uterine fibroid that may follow the UAE that may be linked with tumor infarction and involvement of the endometrial cavity through endometrium. The fact that pregnancy patients underwent UAE has increase rate of spontaneous abortion makes this procedure become controversies for women that have willingness to get pregnant in the future. Recently, there is a latest study of an oral drug of ulipristal acetate (UA). UA (Esmya) is a selective progesterone receptor modulator (SPRM) that has been approved for pre-operative uterine fibroid in reproductive adult women. The duration of administration is limited to 3 months. UA has agonist/ antagonist effect on progesterone depends on the target cells in the endometrium and myometrium to prevent further stimulation of uterine fibroid growth. UA also has a direct effect on myomas by inhibiting cell proliferation and inducing apoptosis, decreasing the size of the myoma. Recommended daily dose is $5 \mathrm{mg}$ to suppress FSH production levels [4].

Associated with uterine fibroids, tranexamic acid is often used in treating excessive menstrual bleeding in women who have uterine fibroids [5]. Tranexamic acid is an antifibrinolytic agent that reduces the menstrual loss. A review of tranexamic acid use in women with fibroids showed that menorrhagia as well as perioperative blood loss in myomectomy may be decreased in women with fibroids. Necrosis and fibroid infarction (especially in large fibroids) after use of tranexamic acid have been documented [6].

As an effective remedy for serious menstrual bleeding, the LNG-IUS has been widely acknowledged. Among several studies, there is general agreement that the use of LNG-IUS in women with fibroids is beneficial in reducing menstrual blood loss, increasing hemoglobin, and alleviating symptoms [7]. Zapata et al. (2010) and Kim et al. (2013) reported higher device expulsion rates due to increased volume of the uterus. However, the low expulsion rate was reported by Jiang et al. [8], [9], [10]. To mediate its effects in tissues, progesterone binds to the progesterone receptor. Progesterone has been shown to function through its receptors to increase the activity of fibroid proliferation. Antiprogestin and agents modulate the activity of progesterone receptors, collectively called SPRM, in the treatment of fibroids, it may be useful. In clinical trials for the treatment of uterine fibroids, multiple SPRMs, including mifepristone, telapristone, asoprisnil, and UA, were used [11], [12].

\section{Case Report}

A 49-year-old woman, P7A0, came with chief complaints vaginal bleeding that has been experienced for 1 year ago and getting worse in 2 months. Her general state was within normal limit and there was no abnormality in physical examination. By vaginal examination, there was blood on the vagina, origin from the external uterine orifice, bimanual examination showed normal size anteflexion uterus, right and left adnexa within normal limits. TVUS finding, uterus anteflexion with size $7.6 \mathrm{~cm} \times 6.04 \mathrm{~cm} \times 5 \mathrm{~cm}$, there was hyperechoic features such as impression coils with a size of $3.4 \mathrm{~cm} \times 3 \mathrm{~cm}$, and both ovaries were in normal size (Figure 1). The laboratory test was done, and there was not any sign of anemia. We diagnosed with submucosal uterine fibroid.
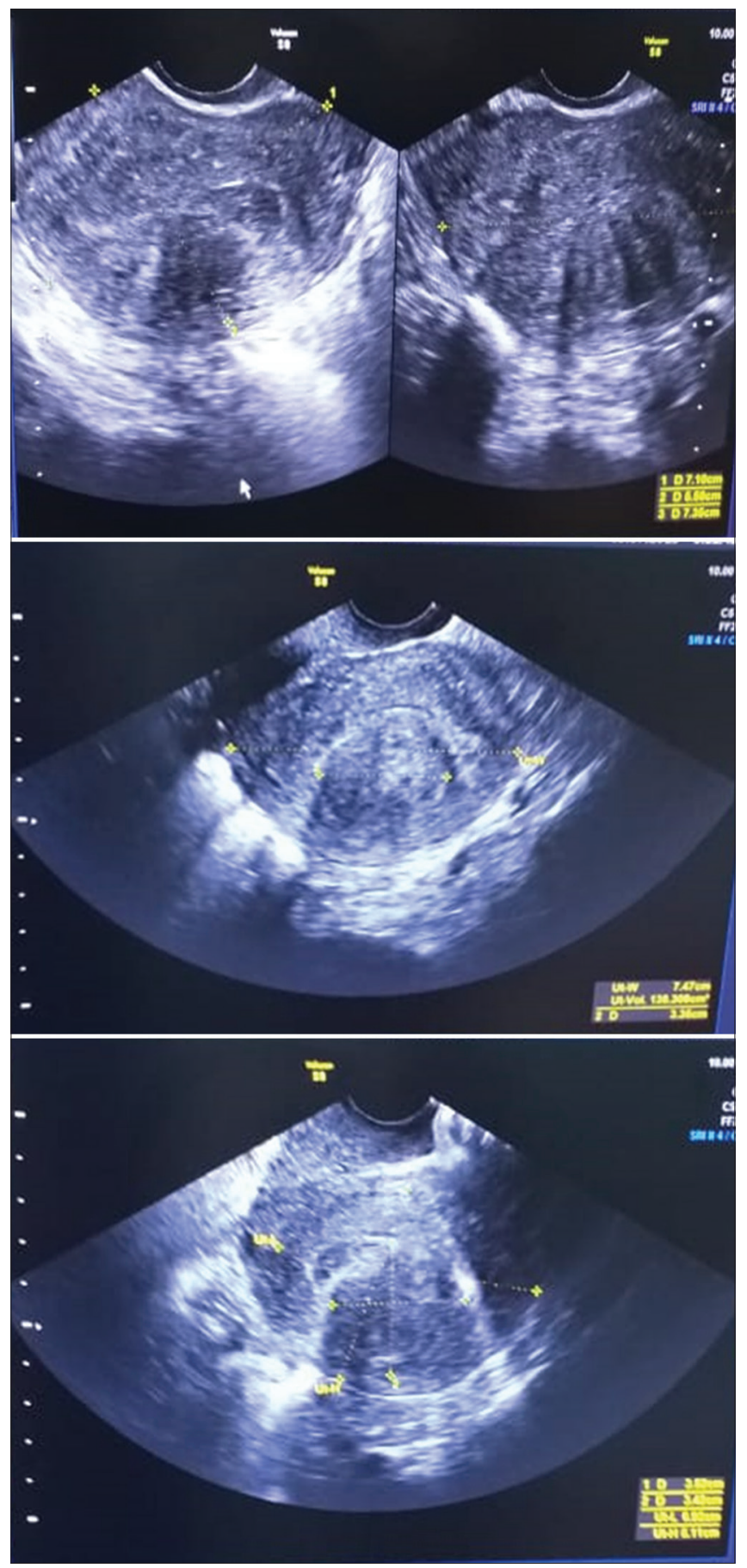

Figure 1: Transvaginal ultrasound shows submucosal uterine fibroid with size $3.4 \mathrm{~cm} \times 3 \mathrm{~cm}$ 
The patient had vaginal bleeding symptoms, then we decided surgical management for this patient, based on age, parity, and willingness to conceive, we decide to perform a hysterectomy for this patient. Transabdominal hysterectomy method was perform consider the patient will undergo bilateral salpingooophorectomy bilateral.

\section{Discussion}

This is the case of a 49-year-old woman diagnosed with uterine fibroid submucosa. The diagnosis is based on the history taking, gynecologic examination, ultrasound, and laboratory examination. Symptoms that arise depend on the location of the uterine fibroid site (cervical, intramural, submucous, and subserous), the size of the tumor and complications that occur. The symptoms can be classified into abnormal bleeding, pain, symptoms and signs of pressure, infertility, and abortion. In this case, some of these symptoms were found. AUB can be caused by several factors including the influence of the ovaries so that endometrial hyperplasia occurs, the surface of the endometrium is wider than usual, endometrial atrophy above the submucosal uterine fibroid, myometrium cannot contract optimally due to uterine fibroid site between the myometrial fibers so that it cannot suppress the vessels of the endometrium between myometrial fibers, so they cannot suppress the blood vessels that pass through it properly. The pain can be caused by impaired blood circulation in the uterine fibroid site, which is accompanied by local necrosis and inflammation.

General condition and vital sign of the patient within normal limit indicate the body has compensated to this chronic bleeding disorders and pain. The decision of hysterectomy related to uterine fibroid made by the appearance of several symptoms such as menorrhagia, metrorrhagia, and patient's preference depends on the patient who is approaching menopause age and does not want to have more children.

Hysterectomy can be done by total abdominal hysterectomy (TAH) or sub-TAH (STAH). Each of these hysterectomy procedures has advantages and disadvantages. STAH is done to avoid a greater risk of surgery, such as heavy bleeding, the trauma of the ureter, bladder, and rectum. However, by doing STAH will leave the cervix, where the possibility of cervical carcinoma can occur. By leaving the cervix, according to the study, data showed that the occurrence of dyspareunia will be lower than those who undergo TAH so that it will still maintain sexual function. By $\mathrm{TAH}$, granulation tissue in the vagina can be a source of vaginal discharge and post-operative bleeding where this condition does not occur in patients undergoing STAH.

\section{Conclusion}

A 49-year-old woman, P7A0, came with chief complaints vaginal bleeding that has been experienced for 1 year ago and getting worse in 2 months. By vaginal examination, there was blood on the vagina, origin from the external uterine orifice. TVUS finding, uterus anteflexion with size $7.6 \mathrm{~cm} \times 6.04 \mathrm{~cm} \times 5 \mathrm{~cm}$, there was hyperechoic features such as impression coils with a size of $3.4 \mathrm{~cm} \times 3 \mathrm{~cm}$. We diagnosed with submucosal uterine fibroid.

We decided surgical management for this patient, based on age, parity, and willingness to conceive, we decide to perform a hysterectomy for this patient. Transabdominal hysterectomy method was perform consider the patient will undergo bilateral salpingo-oophorectomy. Hysterectomy is a progressive and definitive uterine fibroid procedure for women who do not want to conceive and/or women over 40-50 years of age, in particular.

\section{References}

1. van Voorhis B. A 41-year-old woman with menorrhagia, anemia and fibroids: Review of treatment of uterine fibroids. JAMA. 2009;301(1):82-93. https://doi.org/10.1001/jama.2008.791 PMid:19050179

2. AAGL Practice Report: Practice Guidelines for the Diagnosis and Management of Submucous Leiomyomas; 2012.

3. Radeleff B, Eiers M, Bellemann N, Ramsauer S, Rimbach S, Kauczor $\mathrm{HU}$, et al. Expulsion of dominant submucosal fibroids after uterine artery embolization. Eur J Radiol. 2010;75(1):e5763. https://doi.org/10.1016/j.ejrad.2009.07.013

PMid:19692192

4. Younas K, Hadoura E, Majoko F, Bunkheila A. A review of evidence-based management of uterine fibroids. Obstet Gynaecol. 2016;18(1):33-42. https://doi.org/10.1111/tog.12223

5. Peitsidis $P$, Koukoulomati A. Tranexamic acid for the management of uterine fibroid tumors: A systematic review of the current evidence. World J Clin Cases. 2014;2(12):893-8. https://doi.org/10.12998/wjcc.v2.i12.893

PMid:25516866

6. Ip PP, Lam KW, Cheung CL, Yeung MC, Pun TC, Chan QK, et al. Tranexamic acid-associated necrosis and intralesional thrombosis of uterine leiomyomas: A clinicopathologic study of 147 cases emphasizing the importance of druginduced necrosis and early infarcts in leiomyomas. Am J Surg Pathol. 2007;31(8):1215-24. https://doi.org/10.1097/ pas.0b013e318032125e

PMid:17667546

7. Zapata LB, Whiteman MK, Tepper NK, Jamieson DJ, Marchbanks PA, Curtis KM. Intrauterine device use among women with uterine fibroids: A systematic review. Contraception. 2010;82(1):41-55. https://doi.org/10.1016/j. contraception.2010.02.011

PMid:20682142

8. Kim M, Seong SJ. Clinical applications of levonorgestrel-releasing 
intrauterine system to gynecologic diseases. Obstet Gynecol Sci. 2013;56(2):67-75. https://doi.org/10.5468/ogs.2013.56.2.67 PMid:24327984

9. Sangkomkamhang US, Lumbiganon P, Laopaiboon M, Mol BW. Progestogens or progestogen-releasing intrauterine systems for uterine fibroids. Cochrane Database Syst Rev. 2013;2:CD008994. https://doi.org/10.1002/14651858.cd008994.pub2

PMid:23450594

10. Jiang $W$, Shen $Q$, Chen $M$, Wang $Y$, Zhou $Q$, Zhu $X$, et al. Levonorgestrel-releasing intrauterine system use in premenopausal women with symptomatic uterine leiomyoma: A systematic review. Steroids. 2014;86:69-78. https://doi. org/10.1016/j.steroids.2014.05.002

PMid:24832215

11. Donnez J, Tatarchuk TT, Bouchard P, Puscasiu L, Nataliya F, Zakharenko $\mathrm{T}$, et al. Ulipristal acetate versus placebo for fibroid treatment before surgery. N Engl J Med. 2012;366(5):409-20. https://doi.org/10.1056/nejmoa1103182 PMid:22296075

12. Donnez J, Tomaszewski J, Vazquez F, Bouchard $P$ Lemieszczuk B, Baro F, et al. Ulipristal acetate versus leuprolide acetate for uterine fibroids. N Engl J Med. 2012;366(5):421-32. https://doi.org/10.1056/nejmoa1103180

PMid:22296076 